\title{
Gestão do conhecimento no Brasil, em uma empresa global, sob a influência da indústria 4.0
}

\section{Knowledge management in Brazil, in a global company, under the influence of Industry 4.0}

DOI: $10.46932 / \mathrm{sfjdv2n2-174}$

Received in: March 1st, 2021

Accepted in: May 30th, 2021

\author{
Alexandre da Silva Gomes \\ Siemens Energy do Brasil Ltda. Gerente de Projetos. Av. Eng. João Fernandes Gimenes Molina, 1745; \\ 13213-080 Jundiaí, São Paulo, Brasil \\ E-mail: alesilvagomes@gmail.com \\ Mariana Munis de Farias \\ PECEGE - Orientadora de Monografias. Rua Alexandre Herculano, 120 - CEP 13418-445 - Vila \\ Monteiro - Piracicaba, SP, Brasil.
}

\begin{abstract}
RESUMO
Atualmente as empresas com alto valor agregado de mão de obra sofrem com um grande problema, a retenção do conhecimento e a transmissão dele de maneira fluída. Os desafios são grandes com a quantidade de tecnologias emergentes que surgem a todo instante e com a maneira com que as companhias precisam lidar com ela. Este trabalho tem como o objetivo a pesquisa numa empresa global, instalada no Brasil, a respeito de como está se encarando a gestão do conhecimento e a fomentação por meio das ferramentas corporativas e pelos gestores. Também tem-se como objetivo a pesquisa de ferramentas de mercado que possam melhorar essa gestão e fazer com que as companhias caminhem para um futuro dentro do planejado, sem perdas significativas em seu capital intelectual e conhecimento embarcado.
\end{abstract}

Palavras-chave: Gestão do conhecimento, indústria 4.0, tecnologias emergentes, revoluções industriais, ativo intelectual, educação, emprego do futuro

\begin{abstract}
Currently, companies with high value-added labor suffer from a major problem, the retention and transmission of knowledge in a fluid way. The challenges are great with the amount of emerging technologies that arise all the time and the way in which companies need to deal with it. The objective of this work is to research a global company, installed in Brazil, about how knowledge management and fostering is being faced by corporate tools and by managers. It also has as objective the research of market tools that can improve this management and make the companies move towards a future within the planned one, without significant losses in their intellectual capital and embedded knowledge.
\end{abstract}

Keywords: Knowledge management, industry 4.0, emerging technologies, industrial revolutions, intellectual assets, education, employment of the future. 


\section{INTRODUÇÃO}

As quatro revoluções industriais vividas até o final da segunda década do século XXI têm em comum características disruptivas, onde atividades até então feitas de uma maneira, passaram a serem produzidas de um novo modo ou até mesmo, deixaram de ser feitas em prol de uma nova tecnologia, mais rápida, mais barata, menos desgastante ao ser humano ou até mesmo a combinação de vários desses fatores. (LIAO; RAMOS et al.,2017). Tem-se exemplos de locomotivas ou barcos à vapor, onde se via cenas de trabalhadores jogando lenha manualmente em uma fornalha, para conseguir gerar calor e vapor, e assim movimentar tais máquinas, e hoje, tão comumente, foram substituídos por motores elétricos. Em alguns casos mais avançados da tecnologia de automação e digitalização, como a linha 4 do Metrô de São Paulo, por exemplo, além de tudo eletrificado, sequer maquinista possui.

A primeira revolução industrial, ocorrida no século XVIII, caracterizou-se pela mecanização dos maquinários utilizados no então epicentro deste acontecimento, a Inglaterra, onde a indústria de tecelagem era totalmente artesanal, e passou a dispor de teares mecânicos. A produção que era totalmente artesanal, baseada em ateliês, que passou a ser produzida em fábricas, de maneira organizada. A grande contribuição para a primeira revolução industrial foi surgimento da tecnologia à vapor, que permitiu modernizar os teares para um funcionamento agora mecanizado. (DE LIMA; NETO,2017)

A segunda revolução industrial, por sua vez, iniciada no século XX, rompe novas barreiras, com o surgimento da energia elétrica, do petróleo e o uso do aço. A partir do emprego de novas tecnologias e materiais, derivaram-se subprodutos como os combustíveis e produtos químicos a partir do petróleo, motores à explosão, dentre outros diversos adventos da época. Essa revolução, além de apresentar novas soluções e tecnologias, melhoram ou aperfeiçoam tecnologias criadas na primeira revolução, como é o caso das máquinas a vapor, que em sua maioria, passam a ser substituídas por máquinas à combustão, no caso de locomotivas e motores elétricos, amplamente utilizados até os dias atuais na indústria. A partir dessa revolução também surgem modelos de produção como o Fordismo e o Taylorismo. (SCHWAB; DAVIS,2018)

A terceira revolução industrial, penúltima vivenciada pelo homem, iniciada na década de 60 do século XX, tem como característica marcante a eletrônica, que possibilitou a aplicação de vários conceitos que existiam na teoria, mas devido a limitações tecnologias, não eram possíveis de serem aplicados. Com o surgimento da eletrônica, deu-se início ao uso de calculadores poderosas, computadores mais compactos, computação digital, armazenagem de dados, telecomunicação, dentre outras, que possibilitaram a integração de dados em rede, o surgimento da internet, a automação de máquinas, a robotização e diversas outras aplicações. (BARBOSA; ALMEIDA et al.,2018) 
A quarta revolução industrial, teve início no século XXI, e ainda está sendo vivenciado e novas possibilidades estão sendo desvendas em torno dela. Essa revolução define-se pelo conjunto de diversas tecnologias habilitadoras, como Internet das coisas, realidade virtual e aumentada, segurança cibernética, manufatura aditiva, blockchain, computação em nuvem, dentre outras, e vem aproveitando de toda a base criada, a partir da terceira revolução industrial e fazendo aprimoramentos, e em diversos momentos, rompendo com as tecnologias utilizadas, ou até mesmo criando coisas jamais vistas, como é o caso da realidade aumentada. (ROBLEK; KRAPEŽ et al.,2016)

Quanto ao conhecimento, muito se fala de sua gestão, no ambiente organizacional, entretanto ele foi percebido como vantagem competitiva para as companhias apenas a partir da década de 90, onde anteriormente imaginava-se apenas a proteção as ameaças externas, como diferencial competitivo. Um novo olhar para o interior das companhias, juntamente com o aprendizado do indivíduo e consequentemente da organização, culminaram no enfoque à gestão do conhecimento, onde se inicia pela obtenção de dados, transformação em conhecimento, aplicação e desdobramentos e, finalmente, o compartilhamento. (NEVES; NEVES et al.,2018).

Antes preocupadas com os ativos tangíveis, as empresas perceberam que para se manterem competitivas e inovadoras, o ativo intangível passa a ser o alvo a ser buscado. Os retornos obtidos através do conhecimento são a chave para a vantagem competitiva. Importante ressaltar que o conhecimento não se dá logo simplesmente pelo amontoado de dados. O conhecimento é obtido por meio da reunião de dados, analisados criticamente, e com embasamento, fato que faz com que sejam convertidos em informação e consequentemente conhecimento, que por sua vez, vem imbuído de experiência, valores, contextualização e compreensão. (DE SA, FERREIRA et al., 2013)

Para alguns tipos de companhias, a gestão do conhecimento é um fator totalmente inerente ao processo. O desenvolvimento de novos produtos, é um exemplo de processo que depende muito dos sucessos e fracassos do passado, conhecido como lições aprendidas, aliados ao que a empresa tem disponível em termos de conhecimento explícito, ou seja, formalmente guardados por meio de banco de dados, planilhas, publicações, etc., e finalmente o conhecimento e ideias que as pessoas tem em suas mentes, conhecidos como tácito. As montadoras de veículos, por exemplo, adotaram o desenvolvimento integrado, fazendo com seus fornecedores (sistemistas), trabalhem conjuntamente no desenvolvimento de novos produtos. Face a isso, a gestão do conhecimento integrada, vem ganhando papel de destaque em projetos cada vez mais globais, com diversos atores envolvidos, e com um dinamismo e necessidade de que os produtos sejam lançados cada vez mais rápidos. (GATTI JUNIOR; YU, 2017) 
A gestão do conhecimento atualmente, converge totalmente com os objetivos da fábrica inteligente, pregado pelos teóricos da indústria 4.0, sendo que cada vez mais serão exigidas habilidades intelectuais, em detrimento das habilidades manuais. O novo profissional terá que lançar mão de diferenciais intelectuais. Ele deverá ser capaz de obter cada vez mais conhecimento e por sua vez, compartilhá-los, criando assim uma "sociedade do conhecimento". Esses conceitos serão cada vez mais apregoados dentro das empresas, que já perceberam que o capital intelectual e, por conseguinte, a gestão do conhecimento, serão os diferenciais que promovem a vantagem competitiva, essa que, por sua vez, derivada da inteligência competitiva de seus colaboradores, e não de suas máquinas ou processos. (DE ABREU,2018)

Diante de tal quantidade de dados gerados, que crescem exponencialmente a cada minuto, faz-se necessária uma reflexão a respeito da gestão do conhecimento dentro das empresas, com a devida transformação dos dados gerados, em inteligência e conhecimento, para as pessoas e consequentemente para as companhias que delas se beneficiam. (FRAGA; DOS SANTOS et al.,2016)

Quanto à liderança atual nas empresas, é notório que a maneira como é conduzida a gestão do conhecimento, faz toda a diferença quanto aos resultados que podem ser obtidos pela companhia. O bom gestor é o que delega funções intelectuais, dá subsídios para o crescimento do profissional e promove maneiras de o conhecimento ser disseminado vertical e horizontalmente. Entretanto, ainda permanecem gestores com um nível de concentração de informações que, por medo de concorrência, principalmente em empresas de alta tecnologia, não disseminam o conhecimento, segurando assim o desenvolvimento da companhia e consequentemente a vantagem em termos de capital intelectual. (DONATE; DE PABLO,2015)

Com base nos pontos anteriormente abordados, esse trabalho pretende estudar como uma empresa global, instalada no Brasil, atua com gestão do conhecimento, sob a influência da indústria 4.0.

\section{OBJETIVOS ESPECÍFICOS}

a. Estudar de maneira acadêmica os assuntos que auxiliem na resolução do objetivo específico, como gestão do conhecimento e a quarta revolução industrial;

b. Identificar tendências na área da gestão do conhecimento empresarial;

c. Entender, junto aos funcionários de diferentes níveis organizacionais, quais são os desafios e oportunidades e eventuais casos de sucesso já aplicados pela empresa nessa matéria.

d. Propor sugestões de melhoria a empresa global, de modo a melhorar a gestão do conhecimento da empresa. 


\section{MATERIAL E MÉTODOS}

\subsection{QUANTO À ABORDAGEM}

Entende-se por quantitativa a abordagem dessa pesquisa, dado ao fato de estar se manipulando dados obtidos através de Survey e os analisando estatisticamente. Neste caso, temos uma amostragem nãoprobabilística, por julgamento e conveniência, compreendendo todos os níveis hierárquicos do setor de equipamentos de alta tensão, na qual pretende-se analisar os dados como um retrato da população total da empresa, no caso, uma multinacional alemã, instalada no Brasil, do ramo de equipamentos e serviços para o setor de transmissão e distribuição de energia elétrica. Foram entrevistadas pessoas dos departamentos de vendas, engenharia, gerenciamento de projetos, financeiro, controladoria, logística, fábrica, processos, qualidade, compras e pós-vendas (FONSECA, 2002).

\subsection{QUANTO À NATUREZA}

A pesquisa apresentada caracteriza-se por aplicada, dado ao fato de que se quer obter conhecimentos para utilização, no mundo corporativo, de técnicas e ferramentas, com o intuito de trazer possíveis caminhos para as companhias do século XXI, que não querem perder seu ativo intelectual (SILVEIRA; CÓRDOVA, 2009).

\subsection{QUANTO AOS OBJETIVOS}

O objetivo desta pesquisa é exploratório, dado ao fato que se pretende examinar amplamente referências bibliográficas, outrossim a aplicação de pesquisa Survey com o intuito de se obter informações, que contribuam com o levantamento das possíveis causas dos problemas analisados, a saber, a gestão de conhecimento nas empresas, ainda mais com o volume que se imagina obter no século atual (GIL, 2007).

\subsection{QUANTO AOS PROCEDIMENTOS}

O procedimento utilizado neste trabalho foi o de pesquisa com survey. O questionário ficou disponível no período de 17 de maio de 2019, até 28 de junho de 2019, por meio de link disponibilizado por e-mail. https://pt.surveymonkey.com/r/XGFC77P. Foram aplicadas 10 questões de múltipla escolha, com a qual foi possível explorar os temas abordados até então, de maneira a poder entender qual o estágio que a companhia se encontra relativo à gestão do conhecimento e também qual a percepção dos colaboradores com o futuro do mercado de trabalho, sob a ótica da indústria 4.0, e seus desafios para a gestão do conhecimento. O questionário apresentado está disponível no apêndice desta monografia. (SANTOS, 1999).

Doravante, apresenta-se referencial teórico para a pesquisa em epígrafe. 


\section{INDÚSTRIA 4.0 (Educação e emprego)}

Nos dias atuais, as tecnologias se apresentam de maneira assustadoramente rápida, forçando vários setores, dentre eles à indústria, a se moldarem às novas demandas, que trazem consigo uma alta capacidade de respostas a essas demandas. A última grande revolução apresentada no mundo industrial, a quarta, vem carregada de tecnologias de alto valor agregado e que demandam cada vez mais, profissionais altamente qualificados e com alto grau de capacidade de aprendizagem. (ROBLEK; KRAPEŽ et al.,2016)

Diante desse fato, apresenta-se também a educação 4.0, que traz consigo os conceitos que se espera da educação voltada ao atendimento das habilidades futuras, como por exemplo programação, inteligência artificial. Internet das coisas e demais conhecimentos técnicos, assim como habilidades sociais, tais como, inteligência emocional, negociação, trabalho em grupo etc. (GATTI JUNIOR; YU, 2017)

A educação 4.0 apregoa que o sistema de aprendizagem tradicional seja desconstruído, de maneira que o indivíduo esteja no centro e na camada mais externa esteja a sociedade, que se beneficia do indivíduo e por conseguinte é beneficiada por ele. (ADES; BARBOSA, 2018)

O desafio do emprego na era da indústria 4.0 é algo perturbador e bastante preocupante. Com o uso da robotização em substituição a trabalhos repetitivos, perigosos e processuais, haverá um déficit gigantesco dos empregos nas maiores economias mundiais. Outrossim haverá impactos a carreiras com certo nível intelectual, dado ao fato do emprego de inteligência artificial, onde diagnósticos dados por analistas financeiros, ou até mesmo médicos, abrirão espaço para inteligência artificial. (DE ABREU,2018)

Face ao cenário apresentado, a pergunta que se faz é: o que acontecerá com os empregos no futuro? É verdade que haverá uma queda drástica dos empregos com baixo valor intelectual agregado, mas surgirão novas demandas relacionadas a análise de dados. Se destacarão os profissionais que tiveram alta capacidade de entender e gerenciar dados, conseguindo processá-los e encontrar significado, que convirja com o problema que está sendo estudado. (DONATE; DE PABLO,2015)

A empresa do futuro baseará seus produtos e serviços não mais no fluxo (B2C) Business to Consumer e sim no (C2B) Consumer to Business, onde serão cada vez mais levados em conta as especificidades de cada cliente. Não mais haverá produtos que irão atender a todos os consumidores de maneira igualitária. Isso demandará um nível de personalização que demandará análise de dados avançada e uma busca contínua por processos personalizados, fato que demandará profissionais diferenciados. (SCHWAB; DAVIS, 2018)

Importante ressaltar também que com a velocidade de mudança das tecnologias, as carreiras sofrerão mudanças de maneira mais ágil, ou seja, uma profissional do século XXI, doravante deverá estar preparado, em termos de flexibilidade, para mudança de carreira, devido ao impacto nas mudanças de 
tecnologia. RONCATI; MADEIRA et al., 2018).

\section{GESTÃO DO CONHECIMENTO (GC)}

Em se tendo discorrido a respeito das mudanças no mercado de trabalho e educacional com vistas à indústria 4.0, coloca-se aqui a grande necessidade de manutenção do conhecimento dentro das empresas, como fato gerador de vantagem competitiva, em outras palavras, a gestão do conhecimento. (NEVES; NEVES et al.,2018).

Sabe-se que os empregos estão caminhando para um patamar diferenciado, onde os profissionais perseguirão, e deverão, possuir alto valor agregado intelectual, e as companhias, por sua vez, um grande desafio em manter a sua base de conhecimento solida o suficiente para manter sua capacidade competitiva. (DE ABREU,2018)

Diante desse cenário, entende-se que a aplicação de ferramentas de gestão do conhecimento fazse necessária, de maneira que os altos níveis de dados e informações que transitam pela companhia e consequente conhecimento, sejam armazenados e facilmente compartilhados entre os diversos níveis da organização, criando assim uma comunidade de conhecimento, de maneira efetiva. (DE SA, FERREIRA et al., 2013)

Essas ferramentas permitem e permitirão que as companhias mantenham seu maior ativo, a saber, o conhecimento, em alto nível, e farão com que elas tenham condições de manter sua competitividade. Também favorecem a pesquisa e desenvolvimento, assim como a base de dados de erros e acertos de projetos e produtos do passado, com vistas aos desafios do futuro, cada vez mais competitivo e desafiador. (GATTI JUNIOR; YU, 2017)

\section{FERRAMENTAS DE GESTÃO DO CONHECIMENTO}

A empresa estudada nessa pesquisa faz uso da ferramenta Yammer® como ferramenta de GC. Abaixo será feita uma breve apresentação dessa ferramenta, assim como algumas de suas concorrentes, tais como Bitrix24® e AnswerHub®. 


\subsection{YAMMER®}

Figura 1: Yammer® para celular e PC

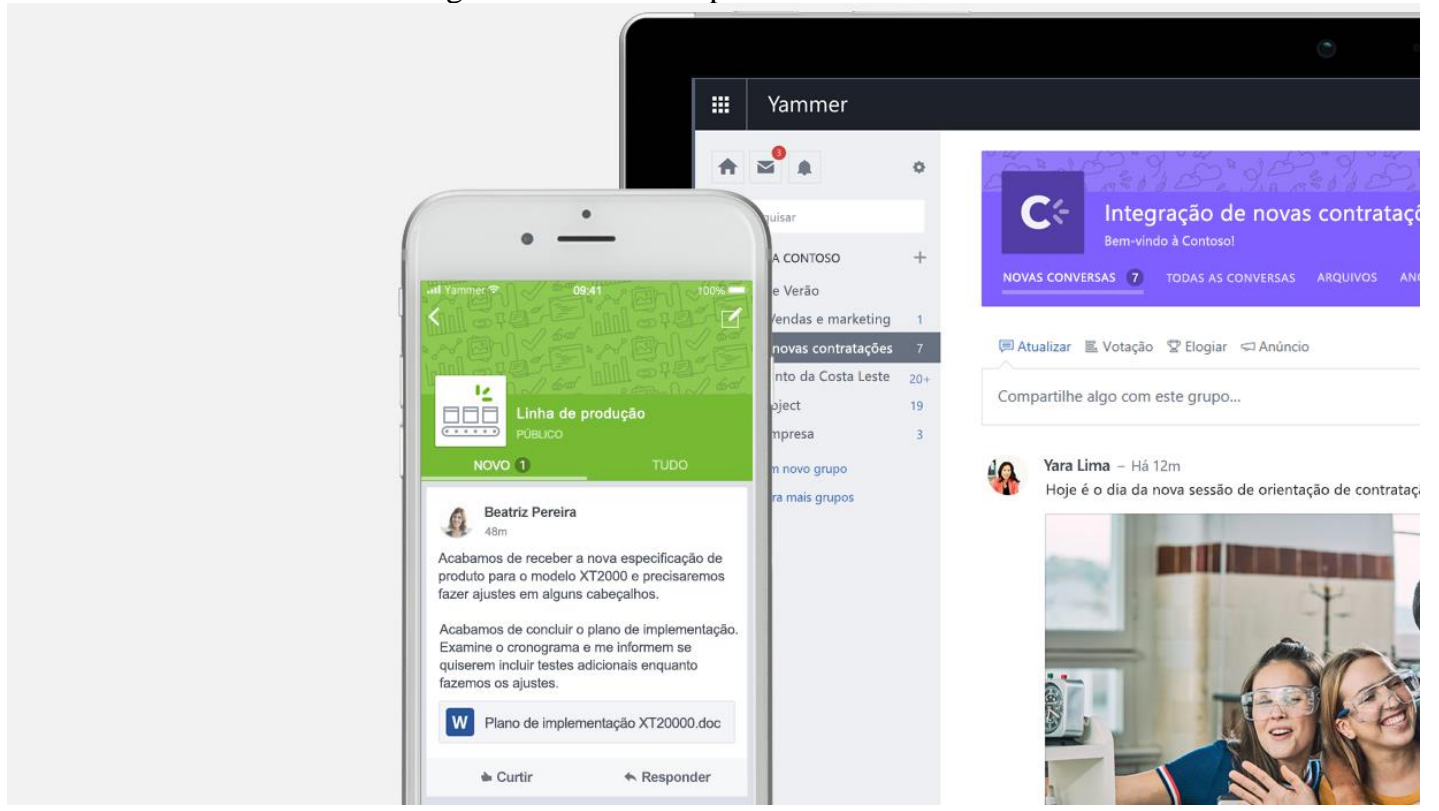

Fonte: Página da internet da Microsoft

O aplicativo é oferecido em diversas plataformas, permitindo que os colaboradores tenham contato contínuo, através de seus telefones portáteis e tablets, ademais dos computadores que utilizam em seu dia a dia, de sua função na companhia.

De acordo com a Microsoft@ (2019), fabricante desta plataforma, o Yammer é capaz de conectar os colaboradores em todos os níveis hierárquicos, de maneira que o conhecimento pode ser compartilhar em fluxo omnidirecional, ou seja, desde a diretoria até o operador de uma máquina, ou vice-versa, podese transmitir conhecimento e também atualizar a todos de projetos e processos em que se está desenvolvendo ou trabalhando no momento e também guardar os que ocorreram no passado.

Figura 2: Aplicativos da plataforma Yammer®

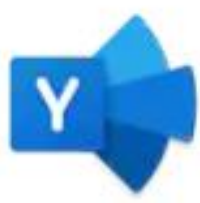

Yammer

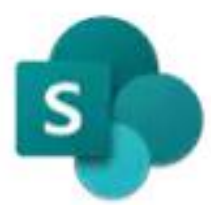

SharePoint

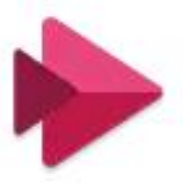

Microsoft Stream

Fonte: Página da internet da Microsoft

O Yammer® é utilizado como painel frontal de apresentação, nos moldes de uma rede social, de maneira que os colaboradores criem suas contas e possam interagir entre eles. É possível compartilhar 
procedimentos e demais documentações formais através do SharePoint ${ }^{\circledR}$, e a produção de conteúdo em vídeo e compartilhamento dentro da comunidade corporativa, lançando mão do Microsoft Stream®. Tudo isso promove um ambiente de compartilhamento de conhecimento, ou GC, que promove também a inovação. (MICROSOFT, 2019)

6.2 BITRIX24®

Figura 3: Portifólio de produtos oferecidos pela Bitrix ${ }^{\circledR}$

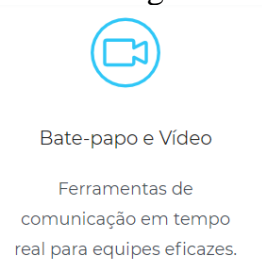

real para equipes eficazes. (a)

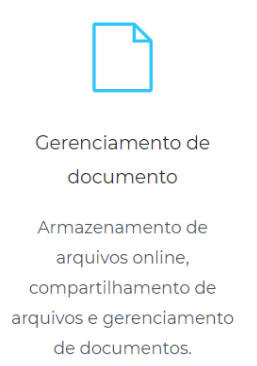

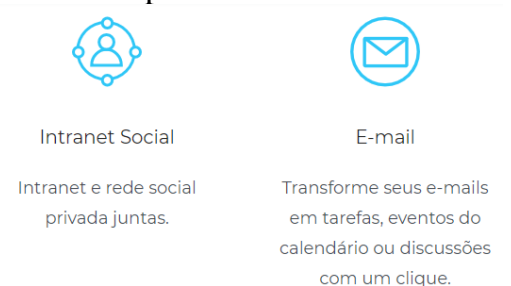

com um clique.

Fonte: Página da internet da Bitrix $\odot$

De acordo com a Bitrix24® (2019), existe uma plataforma de trabalho dotada de diversos recursos que podem ser utilizados em prol da eficiência na comunicação e compartilhamento de dados, consequentemente na gestão do conhecimento. É possível utilizar ferramentas de bate-papo e de vídeo para compartilhamento de dados, assim como armazenar documentos em um gerenciador on line, facilitando assim o fluxo de informações entre os diversos colaboradores da companhia. Como pano de fundo, está a intranet social, integrando todos os colaboradores de maneira simples e objetiva, permitindo assim desenvolver um ambiente colaborativo. (BITRIX24, 2019)

\subsection{ANSWERHUB®}

De acordo com a Devada® (2019), o AnswerHub® é um software baseado em perguntas e respostas, que conecta uma comunidade de desenvolvedores, utilizada para ajudar no compartilhamento de informações e buscar respostas que seriam difíceis de encontrar através de uma busca individual. 
Figura 4: Características oferecidas pelo AnswerHub®

Analytics. Quickly identify and act on trends in user behavior, search activity, time it takes to receive an accepted answer, trends in product adoption, and content performance.

Extensibility. API-first approach, free SDK, full documentation, and integration with various dev workflow tools give companies the ability to create a fully branded experience.

Advanced Moderation. Dynamically organize and control who sees what and ensure the most useful contributions are visible. Automatically approve answers or move questions to a ticket.
Role-Based Permissions. Activate multiple levels of collaboration, from open-to-all access to highly restricted, need-to-know access.

Expert Identification Engine. Identify and enlist knowledgeable experts and automatically route questions to them.

Gamification. Incentivize and reward knowledge sharing and community engagement using reputation scores, rank, badges, and increased privileges.

Fonte: Página da internet da Devada@

Ainda é possível guardar artigos em um repositório que pode ser acessado a qualquer momento, como tutoriais, guias de como fazer, documentos e boas práticas. Também é possível a troca de ideia entre os criadores e os utilizadores, permitindo assim uma melhor assertividade sobre as expectativas daquilo que os clientes vão comprar, esteja em linha com o que estão criando os desenvolvedores. (DEVADA, 2019)

\section{RESULTADOS E DISCUSSÃO}

A empresa alvo da pesquisa trata-se de uma multinacional alemã, com atuação no Brasil a mais de 100 anos, nos seguimentos de energia, automação, digitalização, infraestruturas inteligentes e mobilidade e saúde. Uma empresa com grande experiencia em projetos, produtos e desenvolvimento, com alto valor agregado na mão de obra, e faz investimentos pesados em pesquisa e desenvolvimento.

Doravante, serão apresentados os discorrimentos a respeito dos resultados obtidos através da pesquisa aplicada pela internet aos empregados da empresa estudada. 
Figura 5: Resultado da pergunta 1 aplicada no questionário

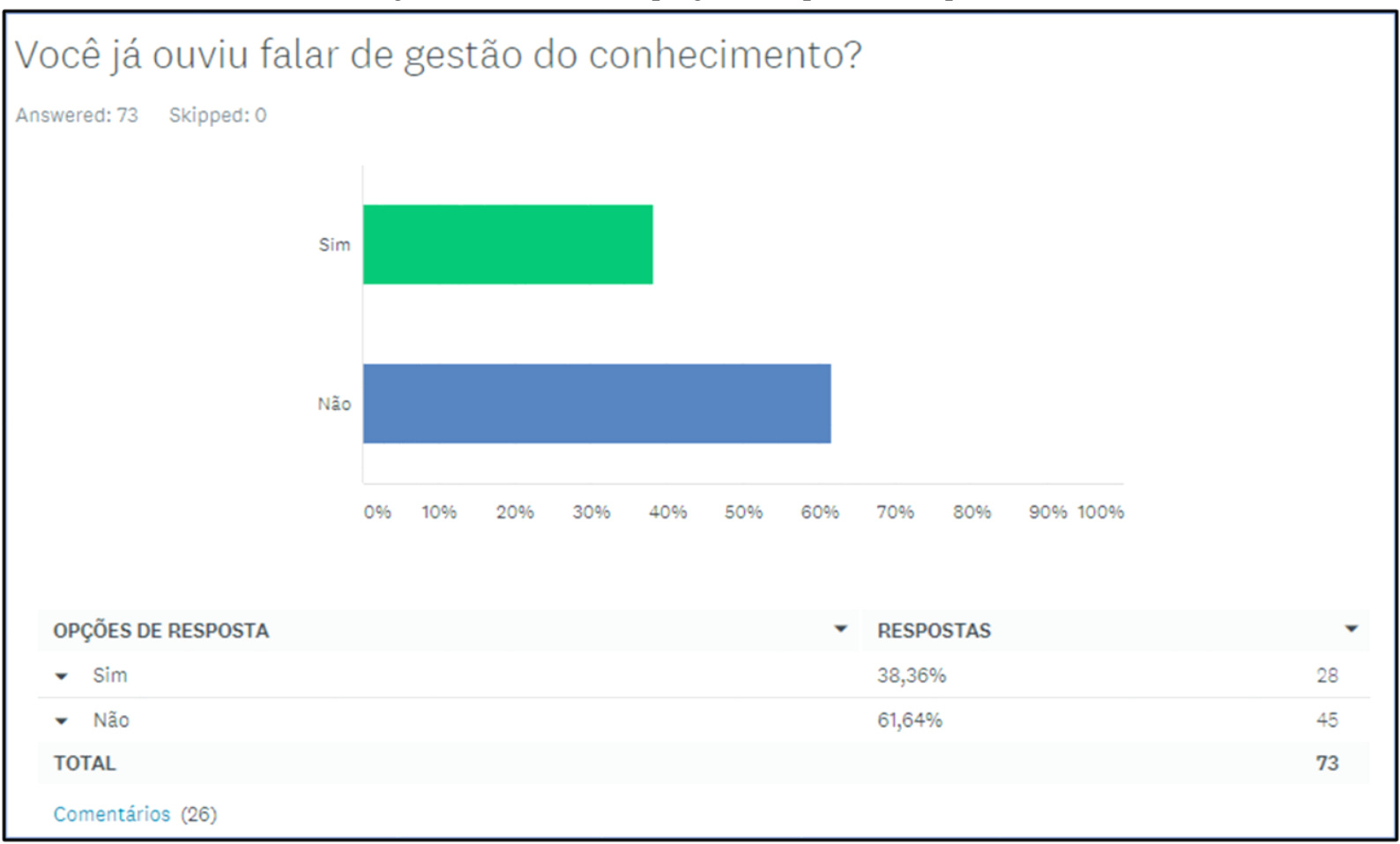

Fonte: Elaborado pelo autor (2019)

Face ao resultado apresentado na primeira questão, é possível perceber que existe um potencial grande a ser explorado na gestão do conhecimento (GC), dado que menos da metade dos pesquisados declaram ter conhecimento sobre o assunto. Esse fato demonstra, a princípio, que a empresa não estaria divulgando corretamente as ferramentas de GC ou até mesmo podendo ser, a própria falta de investimento em ferramentas de gestão, de maneira que os colaboradores sequer tomam conhecimento. Isso pode ser um dado alarmante frente ao que é amplamente difundido a respeito das vantagens competitivas que as companhias produzem através de GC. (DE SA, FERREIRA et al., 2013)

Tabela 1: lista do contato com a GC daqueles que responderam "SIM"

\begin{tabular}{|l|l|}
\hline RESPOSTAS & Revistas, jornais, livros, internet. \\
\hline Treinamentos, vida corporativa etc. & $\begin{array}{l}\text { Métodos aplicados para auxiliar a criação, } \\
\text { manutenção e distribuição de conhecimento de uma } \\
\text { empresa. }\end{array}$ \\
\hline $\begin{array}{l}\text { Assuntos relacionados a área de Recursos Humanos } \\
\text { Gestão de Pessoas. }\end{array}$ & $\begin{array}{l}\text { Um amigo em comum está se especializando. } \\
\text { Conversas com colegas de trabalho. }\end{array}$ \\
\hline Universidade & $\begin{array}{l}\text { Tenho um Artigo escrito sobre a Gestão de } \\
\text { Conhecimento premiado pela ABEPRO. }\end{array}$ \\
\hline Revista Exame & Artigos e Mídia. \\
\hline Curso acadêmico & Site Sebrae. \\
\hline MBA & pelo \\
\hline
\end{tabular}

Fonte: Elaborado pelo autor (2019) 
Figura 6: Resultado da pergunta 2 aplicada no questionário

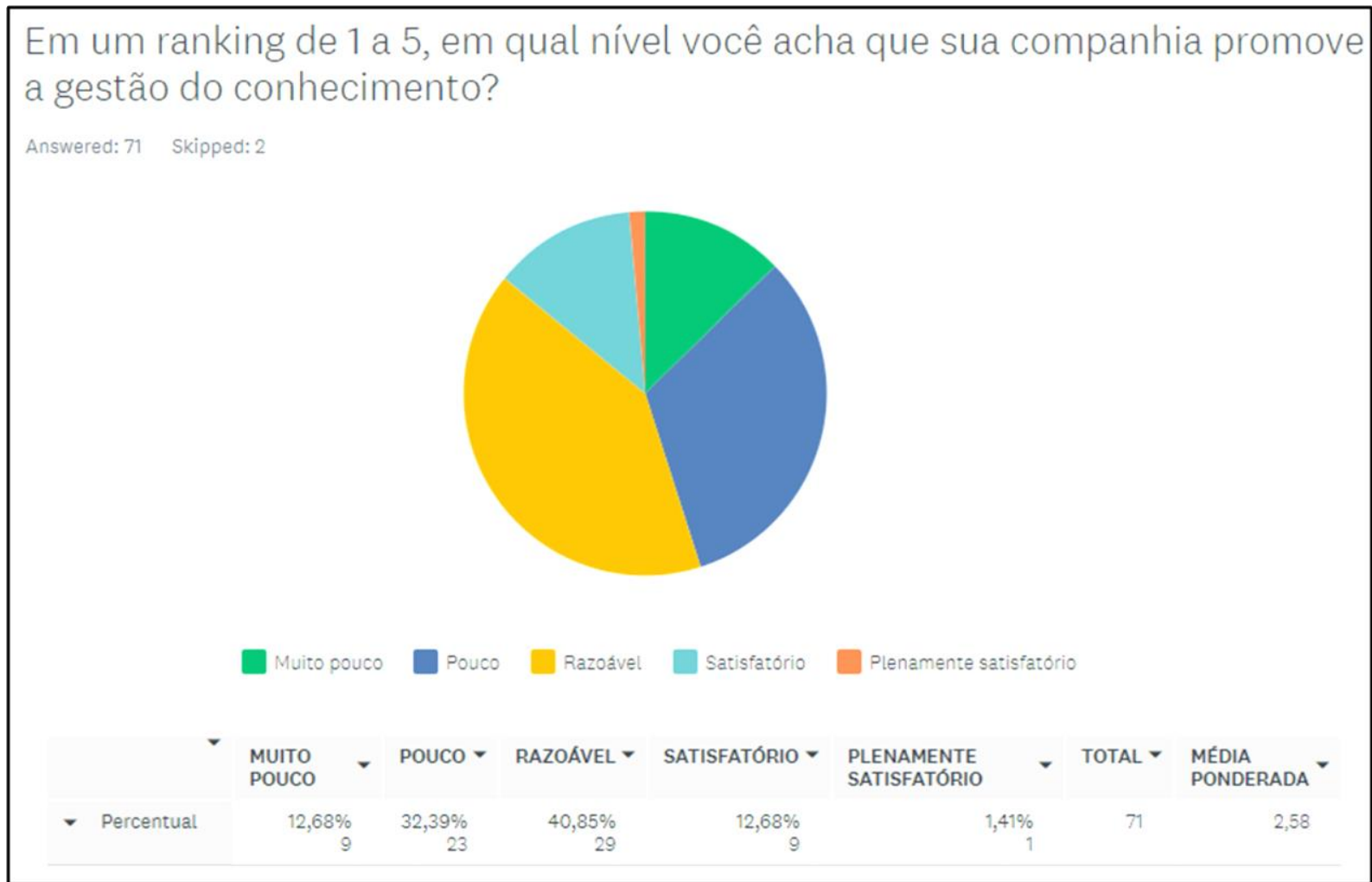

Fonte: Elaborado pelo autor (2019)

Novamente, fica evidente o nível com que os colaboradores enxergam o engajamento da companhia na gestão do conhecimento. Somando "muito pouco" $(12,68 \%)$ com "pouco" $(32,39 \%)$ e "razoável" (40,85\%), tem-se um total de 85,92\% de respostas que não carregam a favor do maior ativo da companhia, a saber, o intelectual, que é algo crucial para uma empresa que vive de engenharia e de produtos engenheirados. A GC é algo devidamente percebido como vantagem competitiva, e não dar a devida atenção para esse tema pode ter danos colaterais que são nocivos ao negócio. (NEVES; NEVES et al.,2018). 
Figura 7: Resultado da pergunta 3 aplicada no questionário

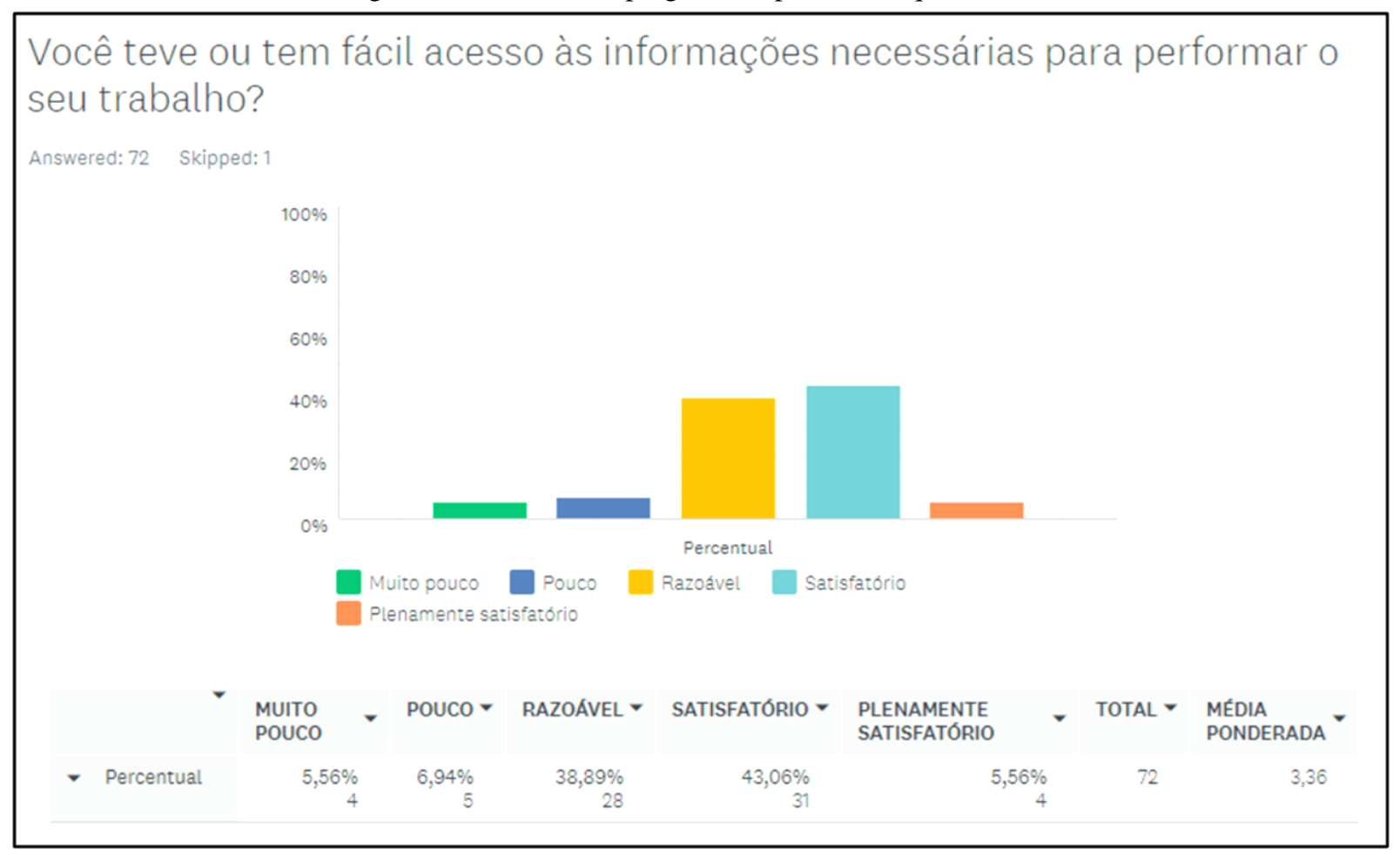

Fonte: Elaborado pelo autor (2019)

Uma empresa com uma ferramenta de gestão de conhecimento bem implementada, pode-se valer disso ao perder um colaborador com alto nível de conhecimento, dado que a facilidade de acesso ao conhecimento, para o novo colaborador que estará substituindo essa posição, é algo que pode encurtar, e muito, o atingimento da mesma performance do colaborador anterior. Na pergunta acima explorada, é possível perceber que os colaboradores não tem relativa facilidade em obter informações para seus trabalhos diários, entretanto isso contrasta com o que foi respondido nas questões anteriores, a respeito do quanto a empresa se dedica à GC, levando a crer que isso não se dá de maneira formal, ou seja, procedimentada e com ferramentas corretas. Basicamente, a leitura que pode ser feita neste caso, é que existe um processo informal de transmissão de conhecimento, que não é algo sólido, na qual a empresa estaria expondo grandemente sua capacidade de retenção de conhecimento. (GATTI JUNIOR; YU, 2017) 
Figura 8: Resultado da pergunta 4 aplicada no questionário

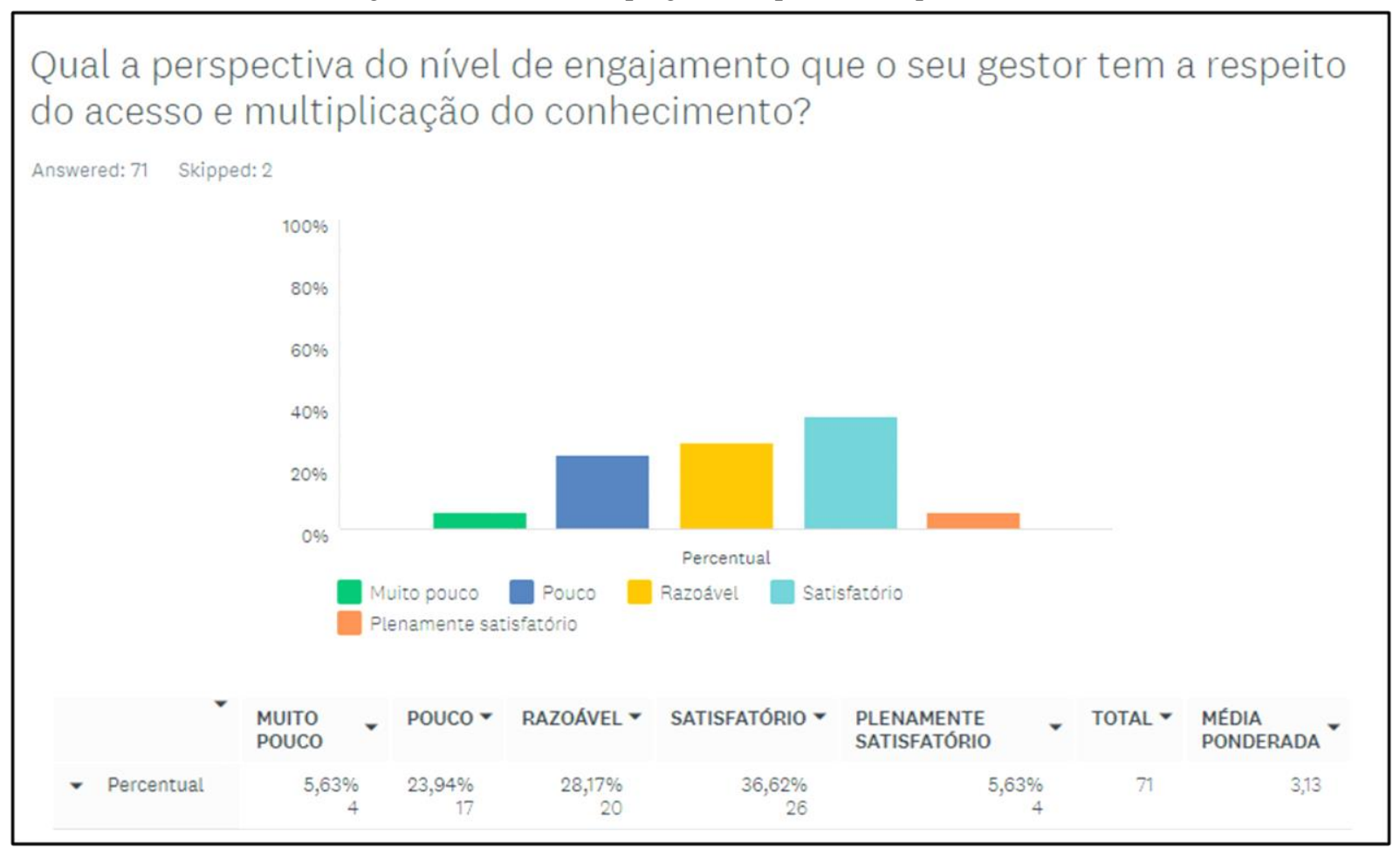

Fonte: Elaborado pelo autor (2019)

Nesse quesito, percebe-se uma preocupação maior na leitura dos colaboradores a respeito do nível hierárquico imediatamente superior, quanto à preocupação dada ao tema de GC na companhia. Isso é algo bom e mostra que existe um grande potencial a ser explorado a respeito da GC nos mais diversos níveis hierárquicos da empresa. Onde há um engajamento expressivo, há uma oportunidade de mostrar a importância do tema e empreender um esforço em torno de uma melhoria contínua, com olhos ao resultado, que nada mais é que a retenção do conhecimento formal e tácito. (GATTI JUNIOR; YU, 2017) 
Figura 9: Resultado da pergunta 5 aplicada no questionário

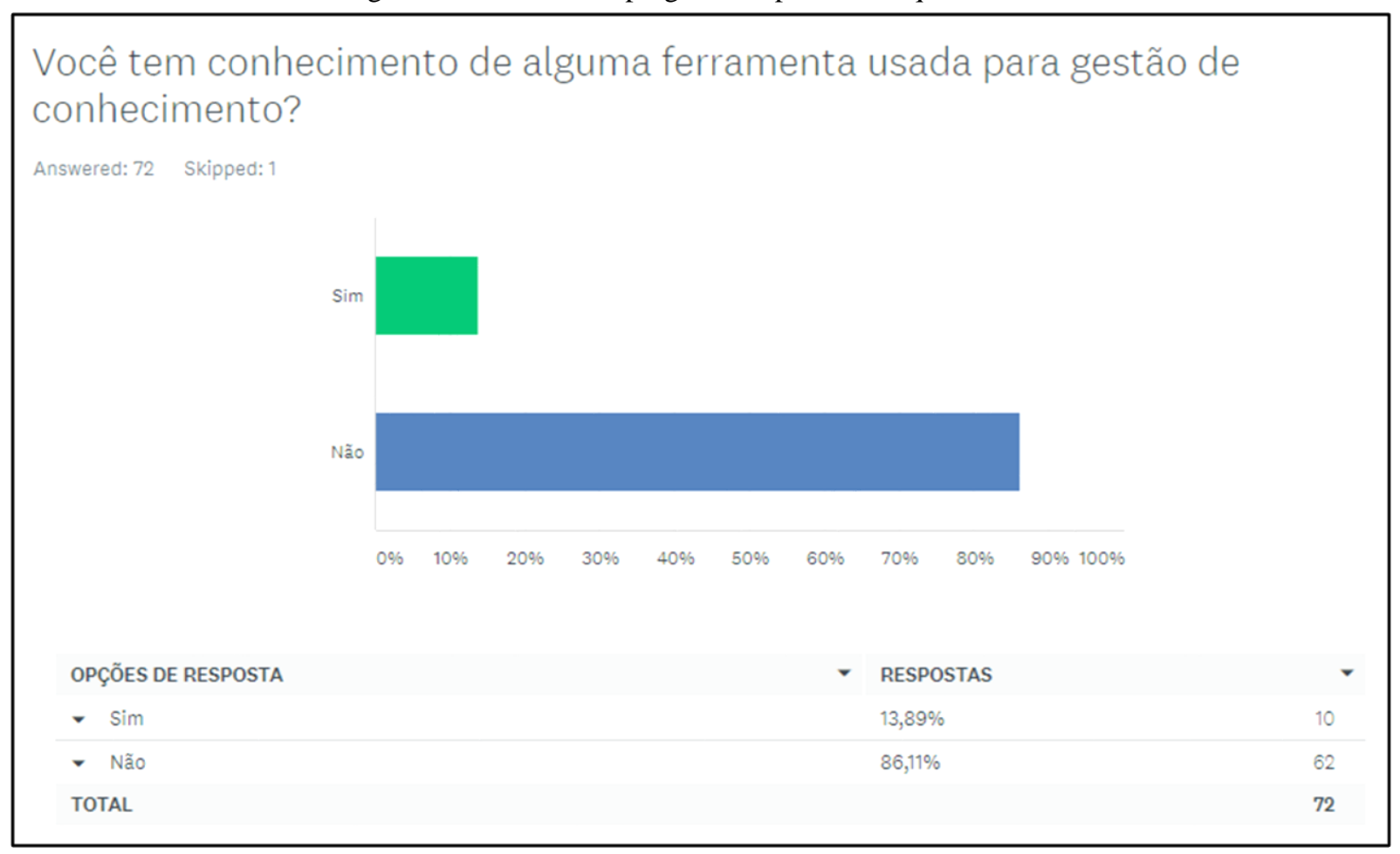

Fonte: Elaborado pelo autor (2019)

Diante do abismo apresentado no gráfico acima, entre conhecer ou não uma ferramenta de GC, fica evidente que o nível de atenção dado atualmente pela companhia, em termos de desdobrar o que está sendo feito nesse quesito e em termos de reciclagem dos colaboradores, notadamente, bem abaixo do esperado.

Para os que responderam SIM, foi solicitado descrever qual ferramenta é de conhecimento do colaborador, na qual são apresentadas as repostas na lista abaixo:

Tabela 2: lista das ferramentas de GC conhecidas pelos pesquisados

\begin{tabular}{|l|l|}
\hline RESPOSTAS & \\
\hline Intranet & Sharepoint \\
\hline SAP & Webnar, Bitrix24, Timeline, Yammer... \\
\hline Bitrix e AnswerHub (SW) & Windchill \\
\hline Digitalização e Ciberfísico & \\
\hline
\end{tabular}

Fonte: Elaborado pelo autor (2019) 
Figura 10: Resultado da pergunta 6 aplicada no questionário

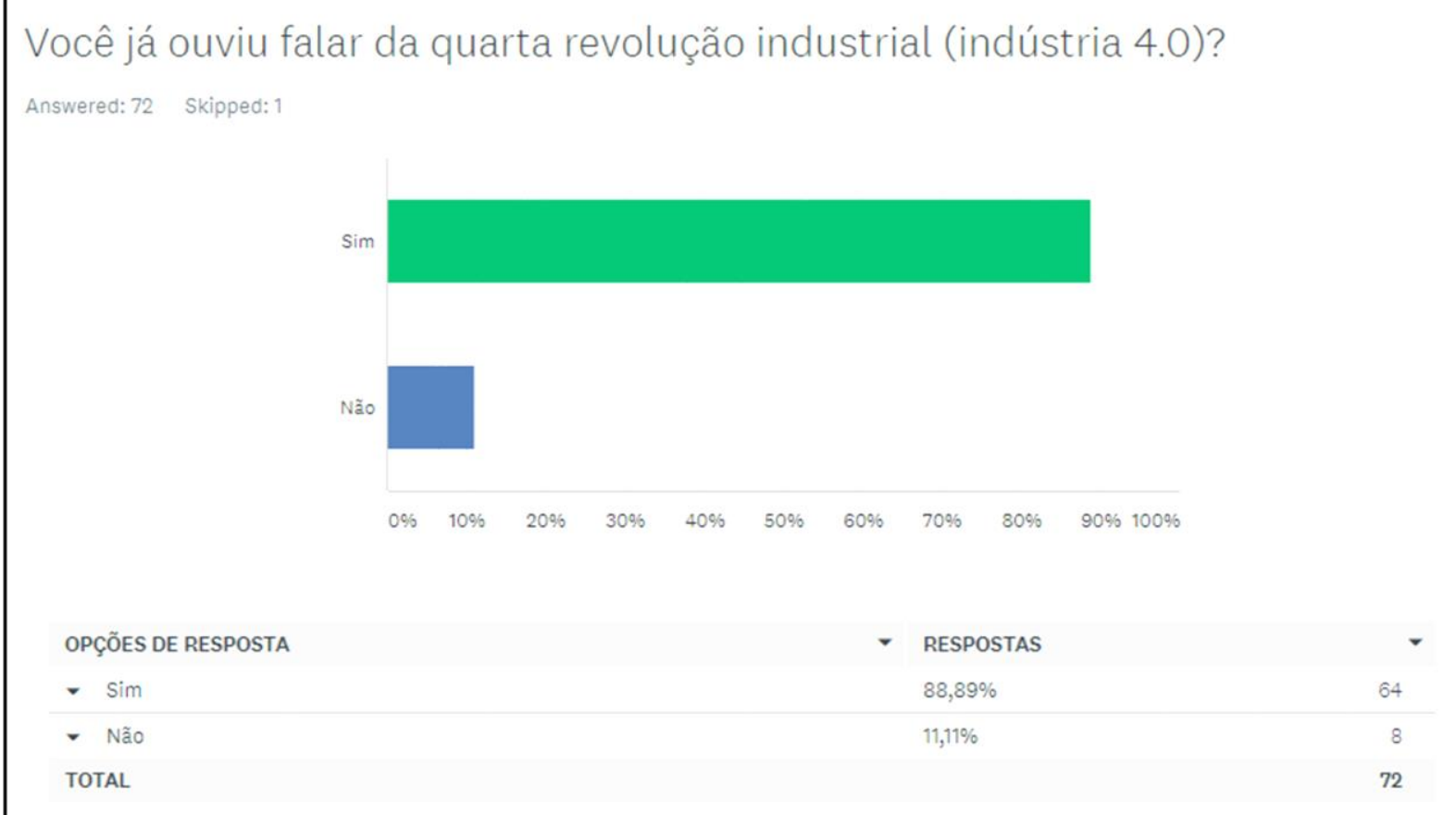

Fonte: Elaborado pelo autor (2019)

Interessante perceber que o tema da quarta revolução industrial está em grande evidência, a ponto de os colaboradores, quase em sua totalidade, já terem ouvido falar. Creio que isso se deve ao fato de que existe uma grande agenda em torno disso, principalmente no Fórum Econômico Mundial, feito por Klaus Schwab, na qual são evidenciados os desafios desse século e como a quarta revolução ajudará a superarmos eles. (SCHWAB; DAVIS,2018) 
Figura 11: Resultado da pergunta 7 aplicada no questionário

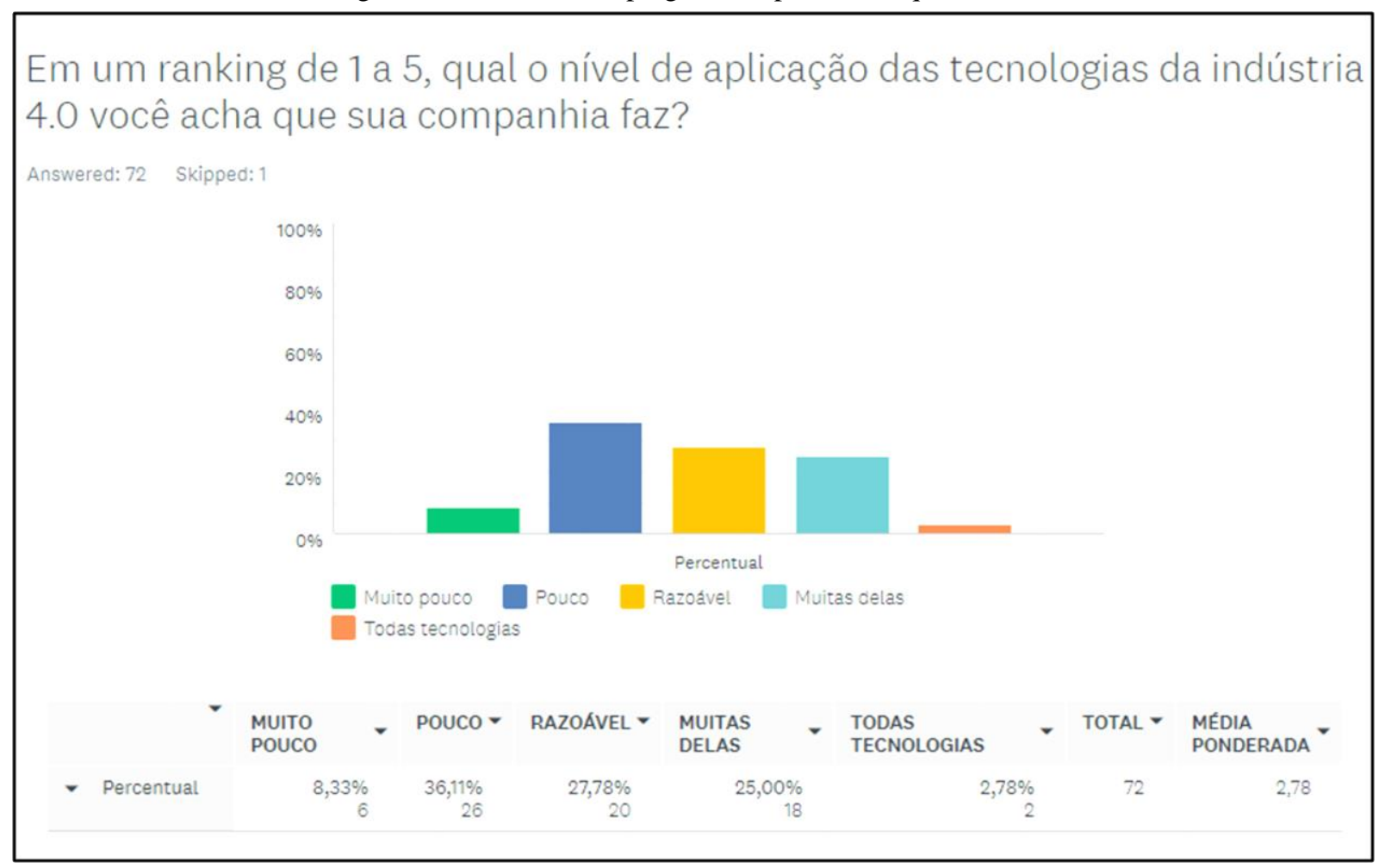

Fonte: Elaborado pelo autor (2019)

Aqui é importante frisar que, como alguns colaboradores não conhecem total ou parcialmente as tecnologias habilitadoras da indústria 4.0, parte das respostas são baseadas em percepções que eles têm de quão avançada está à companhia em termos de aplicação de novas tecnologias para seus desafios relacionados à produção e gestão do negócio. Olhando para os resultados, pode-se observar que a soma do "razoável" com "muitas delas" atinge quase metade dos entrevistados, passando uma percepção boa sobre o que os colaborados acham a respeito da companhia quanto à aplicação das tecnologias da indústria 4.0. (BARBOSA; ALMEIDA et al.,2018) 
Figura 12: Resultado da pergunta 8 aplicada no questionário

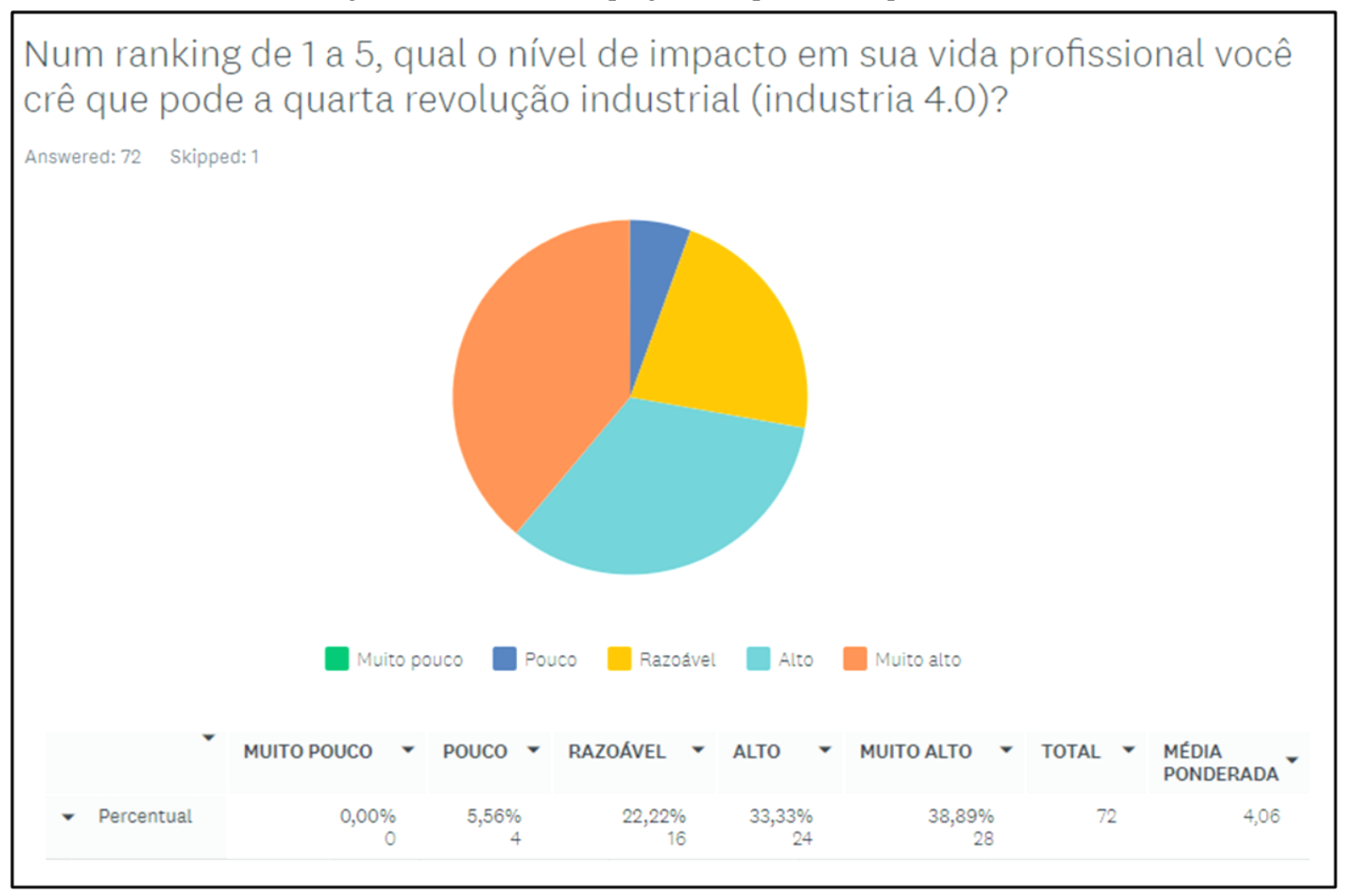

Fonte: Elaborado pelo autor (2019)

Nesta questão é possível perceber que as pessoas estão preocupadas com os resultados oriundos da quarta revolução industrial e o quanto isso pode afetar em suas vidas. Aqui é importante frisar que a preocupação é totalmente associada ao nível de empregabilidade que o colaborador tem ou terá, face aos avanços desenfreados que vem acontecendo com novas tecnologias, e fatalmente deixando aos colaboradores menos preparados, mais expostos à uma possível troca por alguém mais qualificado. (RONCATI; MADEIRA et al.,2018) 
Figura 13: Resultado da pergunta 9 aplicada no questionário

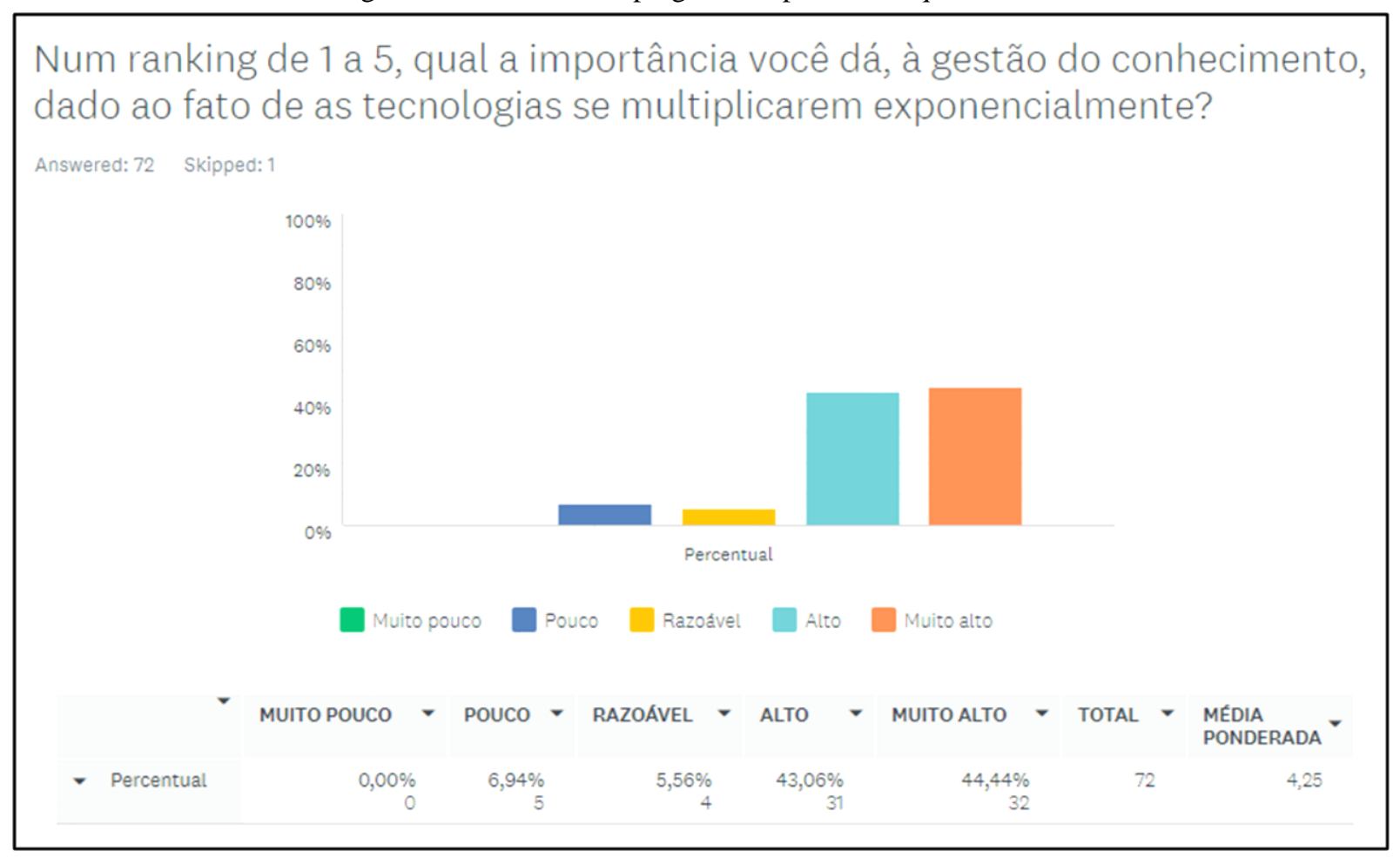

Fonte: Elaborado pelo autor (2019)

É possível frisar que apesar da preocupação com a empregabilidade, os colaboradores da companhia dão a devida importância à gestão do conhecimento, dado aos resultados que mostram que a maioria esmagadora crê que é um tópico muito relevante. De posse dessa informação, é importante que a companhia persiga o caminho da retenção do conhecimento através de ferramentas adequadas, fazendo com que sua própria sobrevivência não seja posta em risco. (NEVES; NEVES et al.,2018) 
Figura 14: Resultado da pergunta 10 aplicada no questionário

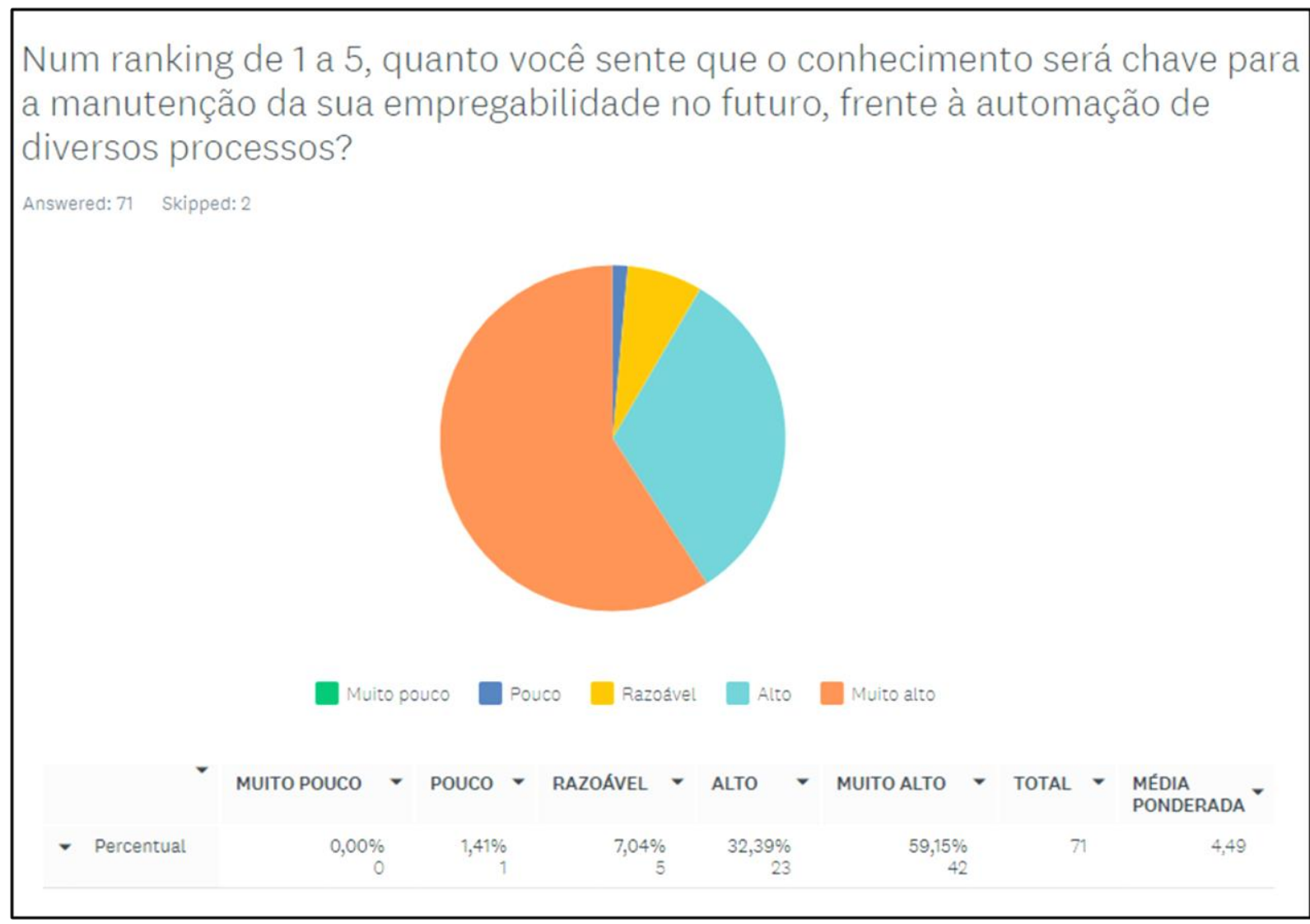

Fonte: Elaborado pelo autor (2019)

O discorrimento sobre os resultados dessa questão sequer seria necessário, dado a realidade dos fatos, onde é nítido a preocupação dos colaboradores com a empregabilidade associada aos conhecimentos que precisarão ser adquiridos, devido as tecnologias emergentes e as vindouras. A educação nos moldes atuais, aparentemente já não atendem ao que a sociedade do futuro espera, com rápidas atualizações e alta flexibilidade para se adaptar a novas situações. (ADES; BARBOSA,2018)

Entre as ferramentas aqui apresentadas, a percepção é de que o Yammer® seria a melhor ferramenta para empresas dos mais diversos setores, já que aparentemente ela se enquadra na maioria das aplicações, sendo de fácil acesso e utilização, e com ferramentas de grande relevância para o compartilhamento e manutenção do conhecimento. Outrossim, o AnswerHub® apresenta um alto nível de aprofundamento técnico em seus fórum e discussões, sendo mais recomendado para empresas de softwares e desenvolvedores. A princípio as 2 ferramentas poderiam ser aplicadas numa companhia, de igual maneira, entretanto dependeria do quanto a companhia estaria disposta a investir nesse quesito.

\section{CONCLUSÕES}

Como objetivo final, este trabalho tinha a pesquisa e a apresentação de possíveis métodos e 
ferramentas, com a qual a companhia pesquisada e demais empresas pudessem se valer em seus processos como forma de manutenção e compartilhamento do conhecimento.

As revoluções industriais inicialmente espaçadas de séculos entre elas, cada vez mais acontecem em menor intervalo de tempo e com uma quantidade exponencial de novas tecnologias. As empresas que pensam em ser competitivas no futuro, precisam estar preparadas para lidar com essa demanda. (SCHWAB; DAVIS,2018)

A educação dos moldes atuais já não se mostra suficiente para preparar os profissionais do futuro, que deve ter alta capacidade de absorver tecnologias emergentes, numa velocidade cada vez maior e por fim, com uma flexibilidade jamais vista antes, dado ao fato de algumas desaparecerem tão rápido quanto seu surgimento. (ADES; BARBOSA, 2018)

A empregabilidade do futuro estará voltada totalmente para profissionais com alto valor agregado em termos de conhecimento. Não haverá espaço para tarefas repetitivas, que serão performadas de maneira automatizada, por robôs. Nesse sentido, o profissional do futuro precisará estar sempre atento às mudanças de forma muito ágil, com alta capacidade de adaptação e com habilidades cada vez mais apuradas. (RONCATI; MADEIRA et al.,2018)

A gestão do conhecimento se mostra uma peça chave, fundamental para as companhias se manterem competitivas no mercado. As empresas precisarão explorar e ir cada vez mais a fundo nesse tema, já que algumas delas tem em seu portifólio somente ativos virtuais, como software, por exemplo, na qual sequer máquinas são usadas. Para esse tipo de empresa, a gestão do conhecimento é uma questão de sobrevivência, e a manutenção dela, o ar que ela vai precisar para respirar. As ferramentas aqui apresentadas podem contribuir com essa demanda, fazendo com que as empresas mantenham seu maior ativo, a saber, o conhecimento, como sua maior vantagem competitiva. (GATTI JUNIOR; YU, 2017)

A pesquisa aplicada na companhia mostra que, apesar de estarmos falando de uma empresa altamente inovadora e de vanguarda, diversos colaboradores sequer haviam ouvido falar a respeito de GC e ferramentas associadas a ela. Uma recomendação seria que a companhia divulgasse a real importância da GC e do uso da ferramenta adquirida, fato que demandou altos investimentos em nível mundial. Aqui é possível perceber que não basta comprar e disponibilizar uma ferramenta, é necessário demonstrar individualmente a importância para a empresa, do compartilhamento e manutenção do conhecimento.

Recomenda-se como uma nova pesquisa a ser feita na companhia, a utilização de vídeos como forma de compartilhamento de conhecimento, que são bastantes didáticos e de fácil assimilação. O próprio pacote do Yammer@ tem um módulo dedicado a isso, a saber, o Microsoft Stream ${ }^{\circledR}$, que é uma ferramenta aparentemente com baixo uso na atualidade. 


\section{AGRADECIMENTO}

Agradeço a Deus primeiramente, pela condição de poder chegar a um ponto que antes era impensável para mim. Agradeço a minha família, que é minha base e não menos importante, minha orientadora, pela paciência e ensinamentos. 


\section{REFERENCIAS}

Liao, Yongxin; Deschamps, Fernando; Loures, Eduardo de Freitas Rocha; Ramos, Luiz Felipe Pierin, 2017. Past, present and future of Industry 4.0 - a systematic literature

review and research agenda proposal. International Journal of Production Research, DOI: 10.1080/00207543.2017.1308576,

De Lima, Elaine Carvalho; Neto, Calisto Rocha De Oliveira, 2017. Revolução Industrial: considerações sobre o pioneirismo industrial inglês. Revista espaço acadêmico, n. 194: 102-113.

Schwab, K.; Davis, N. 2018. Aplicando A Quarta Revolução Industrial. 1ed. Editora Edipro, São Paulo, SP, Brasil.

Barbosa, M.T.J.; Baisso, M.; Almeida, M. T. 2018. Surge uma nova sociedade. p. 3-11. In: Silva, E.B.; Scoton, M.L.R.P.D.; Pereira, S. L., Dias; E.M. Automação \& Sociedade: Quarta Revolução Industrial, um olhar para o Brasil. Brasport, Rio de Janeiro, RJ, Brasil.

Roblek, Vasja; Meško, Maja; Krapež, Alojz, 2016. A Complex View of Industry 4.0. SAGE Open, DOI: $10.1177 / 2158244016653987$.

Neves, Maria Lúcia Corrêa; Nora, Gabriela Almeida Marcon; Trzeciak, Dorzeli Salete; Neves, Elpídio Ribeiro, 2018. Gestão do conhecimento no brasil: a abordagem dos textos jornalísticos. Perspectivas em Gestão \& Conhecimento, v. 8, n. 3: 228-242.

De Sá, Fabiano Bento; Bento, Karina Gomes dos Reis; Ziviani, Fabrício; Ferreira, Marta Araújo Tavares, 2013. Práticas de gestão do conhecimento: um estudo em organizações mineiras. Perspectivas em Gestão \& Conhecimento, v. 3, n. 1: 114-131.

Junior, Wilian Gatti; Yu, Abraham, 2017. As transformações do conhecimento no processo de inovação: um estudo multicasos no desenvolvimento da tecnologia flex fuel no Brasil. REGE - Revista de Gestão, v. 24: 256-267.

De Abreu, Paulo Henrique, 2018. Perspectivas para a gestão do conhecimento no contexto da indústria 4.0. South American Development Society Journal, v.4, n.10: 126-145.

Fraga, Bruna Devens; Erpen, Julio Graef; Varvakis, Gregorio; Dos Santos, Neri, 2016. Business Intelligence: métodos e técnicas de gestão do conhecimento e as tendências para avanços do capital intelectual. Navus, v.7, n.1: 43-56.

Donate, Mario J.; de Pablo, Jesús D. Sánchez, 2014. The role of knowledge-oriented leadership in knowledge management practices and innovation. Journal of Business Research v. 68: 360-370.

Fonseca, J. J. S. 2002. Metodologia da pesquisa científica. UEC, Fortaleza, CE, Brasil.

Silveira, D. T.; Córdova, F. P., 2009. A pesquisa científica. p. 31-42. In: Gerhardt, T. E.; Silveira, D. T. Métodos de pesquisa. UFRGS, Rio Grande do Sul, RS, Brasil.

Gil, A. C. 2007. Como elaborar projetos de pesquisa. 4ed. Atlas, São Paulo, SP, Brasil. 
Santos, A. R. 1999. Metodologia científica: a construção do conhecimento. DP\&A, Rio de Janeiro, RJ, Brasil.

Ades, C.; Barbosa, C. 2018. O desafio da educação na quarta revolução industrial. p. 227-247. In: Silva, E.B.; Scoton, M.L.R.P.D.; Pereira, S. L., Dias; E.M. Automação \& Sociedade: Quarta Revolução Industrial, um olhar para o Brasil. Brasport, Rio de Janeiro, RJ, Brasil.

Roncati, J.; Silva, M. T. A.; Madeiro, F. 2018. O desafio dos empregos na quarta revolução industrial. p. 211-225. In: Silva, E.B.; Scoton, M.L.R.P.D.; Pereira, S. L., Dias; E.M. Automação \& Sociedade: Quarta Revolução Industrial, um olhar para o Brasil. Brasport, Rio de Janeiro, RJ, Brasil.

Office Yammer® [Microsoft $\left.{ }^{\circledR}\right]$. 2019. Rede social empresarial. Disponível em: <https://products.office.com/pt-br/business/teamwork/enterprise-social-network?SilentAuth=1

>. Acesso em: 29 set. 2019.

Comunicação [Bitrix24®]. 2019. Rede social empresarial. Disponível em: < https://www.bitrix24.com.br/tools/communications/top-collaboration-tools.php >. Acesso em: 29 set. 2019.

DEVADA [AnswerHub®]. 2019. Comunidade de desenvolvedores. Disponível em: < https://devada.com/answerhub/features/ >. Acesso em: 29 set. 2019. 